Gazi Üniversitesi
Fen Bilimleri Dergisi
PART C: TASARIM VE TEKNOLOJI
dergipark.gov.tr/http-gujsc-gazi-edu-tr

\title{
Altı Serbestlik Dereceli Bir Aydınlatma Manipülatörünün Yapay Sinir Ağları Temelli Ters Kinematik Çözümü ve Benzetimi
}

\author{
Nihat ÇABUK ${ }^{1}$, Veli BAKIRCIOĞLU ${ }^{1, *}$ \\ ${ }^{I}$ Aksaray Üniversitesi, Teknik Bilimler Meslek Yüksekokulu, Elektrik ve Enerji Bölümü, 68100, Aksaray
}

\begin{abstract}
$\ddot{O} \mathbf{z}$
Makale Bilgisi

Başvuru: 14/07/2017

Düzeltme: $21 / 12 / 2017$

Kabul: 21/01/2018

Anahtar Kelimeler

6-DOF Manipülatör Kinematik Analiz,

Robot manipülatörlerinde ters kinematik problem, manipülatörün uç işlevcisinin istenilen konumda olması için eklem değişkenlerinin hesaplanmasını içeren doğrusal olmayan bir problemdir. Ters kinematik problemin çözümü robotlarda başlıca zorluklardandır. Bazı manipülatör konfigürasyonlarında bu problemin çözümü zor da olsa mümkün olabilirken bazı konfigürasyonlarda mümkün olamamaktadır. Bu çalıșma 6 serbestlik dereceli (6-DOF) bir aydınlatma robotunun ters kinematik probleminin yapay sinir ağları (YSA) temelli çözümünü amaçlamaktadır. Aydınlatma robotu olarak ifade edilen bu robot, tıbbi operasyon alanında istenilen bölgeyi aydınlatmak için kendiliğinden aydınlatma görevini yapmaktadır. Aydınlatma için kullanılan manipülatör bilgisayar destekli tasarım (CAD) programında tasarlanmış olup Simulink ortamına aktarılmıştır. Bu sayede, geliştirilen YSA modelinin uygulaması Simulink ortamında gerçekleştirilmiştir. Elde edilen sonuçlar grafiksel olarak verilmiştir. Elde edilen sonuçlara göre, tasarlanan modelin makul sonuç verdiği gözlemlenmiştir.
\end{abstract}

Ters Kinematik,

Yapar Sinir A Ălart

Keywords

6-DOF Manipulator, Kinematic Analysis,

Inverse Kinematic,

Artificial Neural Networks

\section{Artificial Neural Networks Based Inverse Kinematics Solution and Simulation of a Six Degree of Freedom Lighting Manipulator}

\begin{abstract}
Inverse kinematics problem of a robot manipulator is calculation of joint variables of the manipulator. Inverse kinematic is a challenging problem of robots. The inverse kinematics in robotic is the determination of joint angles for a desired position of the end effector. This paper proposes an Artificial Neural Network (ANN) model to find Inverse kinematic solution of a 6DOF manipulator, which is designed instead of a manually lighting system that is used in surgery rooms. After obtaining forward kinematic equations, these equations were used to derive training data of ANN. The manipulator was designed in a computer aided design (CAD) program and this CAD model transferred to Simulink environment for a realistic and visual simulation purpose. To evaluate the trained ANN performance visually, this Simulink model were used. A test input set is introduced to the trained ANN. Results are discussed and demonstrated graphically. It was observed that obtained results are satisfactory, and the error of ANN for a reference position is acceptable.
\end{abstract}

\section{GIRISș}

Tıbbi operasyonların aydınlatmasında kullanılan aydınlatma başlıklarının konumlandırılması elle yapılmaktadır. Operasyon esnasında elle yapılan bu konumlandırma işlemi, operatöre ek bir iş yükü çıkarmaktadır. Aydınlatma işinin operatörün isteğine bağlı olarak kendiliğinden gerçekleşmesi, operatöre ek bir iş yükü çıkmamasını sağlayacaktır. Bu sebeple, tıbbi operasyonlarda kullanılmak üzere mevcut sistemin konfigürasyonu ve serbestlik derecesine bağımlı kalarak bir aydınlatma manipülatörü tasarlanmıştır. Tasarlanan manipülatörün kontrolcü tasarımı için ters kinematik probleminin çözümü gerekmektedir. Ters kinematik, robotik uygulamalarının en zor problemlerindendir. Şekil 1'de gösterildiği gibi, ters kinematiğin amac1, bir manipülatörde çalışma uzayında istenilen konum ve yönelimlerin gerçekleşmesi için gerekli olan eklem değişkenlerinin belirlenmesidir. Manipülatörün geometrisi ve serbestlik derecesi sayısı bu problemlerin zorluğunu etkilemektedir. 
Eklem uzay

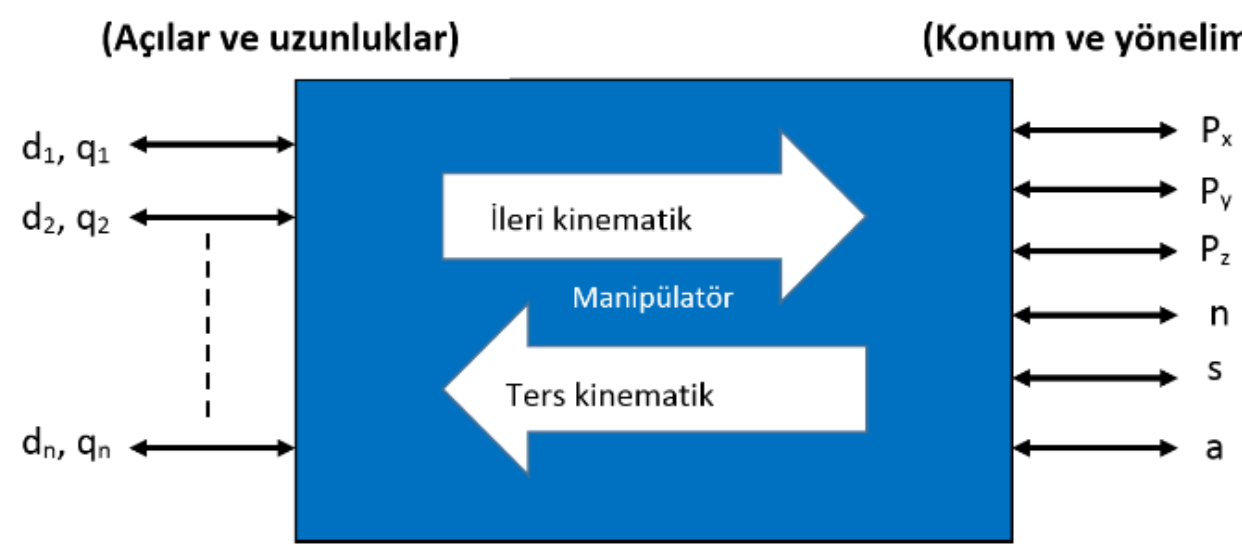

Şekil 1. Kinematik ilişkinin şematik gösterimi

\section{Kartezyen uzay}

\section{(Konum ve yönelimler)}

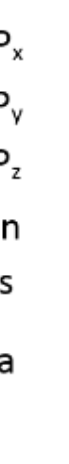

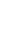

\begin{abstract}
Manipülatörlerin yönelime bağlı ters kinematik probleminin birden çok çözümü vardır. Bu yüzden manipülatörlerde kontrol edilebilirlik oldukça zor olmaktadır. Ayrıca, analitik veya geometrik yöntemlerle çözümlenmesinde zorluk çekilen ya da bu yöntemlerle çözümlenemeyen ters kinematik problemlerin çözümünde genellikle iteratif yöntemler kullanılmaktadır. Literatürde yapılan çalışmalarda ters kinematik probleminin çözüm yöntemi olarak iteratif yöntemlerden olan yapay sinir ağları (YSA) temelli birçok yayın bulunmaktadır [1-16]. YSA sadece robotik uygulamalarda değil, bir sistemin giriş değişkenleri ile çıkış değiş̧kenleri arasındaki ilişki kurma temeline dayanan doğrusal olmayan birçok karmaşık problemin çözümünde de kullanılmaktadır [17-20].
\end{abstract}

$\mathrm{Bu}$ çalışmada, tıbbi operasyonlarda kullanılmak üzere tasarlanmış olan altı serbestlik dereceli bir manipülatörün ters kinematik probleminin YSA temelli çözümü sunulmuştur. Tasarım aşamasında, manipülatörün boyutlandırılması, tıbbi operasyonların gerçekleştirildiği ortamın fiziki boyutları göz önüne alınarak yapılmıştır. Elde edilen bu model üzerinden ileri kinematik hesabı yapılarak ters kinematik çözümünde kullanılan YSA için gerekli veri elde edilmiştir. Elde edilen verilerle eğitilen YSA'nın performans1 Matlab/Simulink ortamında değerlendirilmiştir.

Makalenin sunumu şu şekildedir; ikinci bölümde, aydınlatma manipülatörünün fiziksel özellikleri verilmiştir. İleri kinematik hesabı ve çalışma uzayı bu bölümde anlatılmıştır, ayrıca ters kinematik probleminin çözümü için tasarlanan ve eğitilen YSA modeli ve parametreleri de bu bölümde verilmiştir. Eğitilen YSA modelinden elde edilen sonuçlar grafiksel olarak üçüncü bölümde verilmiştir, buna ek olarak YSA'nın performans değerlendirmesi yine bu bölümde yapılmıştır. Önerilen yöntemin etkinliği ise son bölümde tartışılmıştır

\section{MATERYAL VE METOT}

$\mathrm{Bu}$ başlık altında, aydınlatma manipülatörünün fiziksel özellikleri verildikten sonra ileri kinematik hesaplamaları yapılmıştır ve ters kinematik probleminin çözümünde kullanılan YSA ve eğitimi hakkında bilgiler verilmiştir.

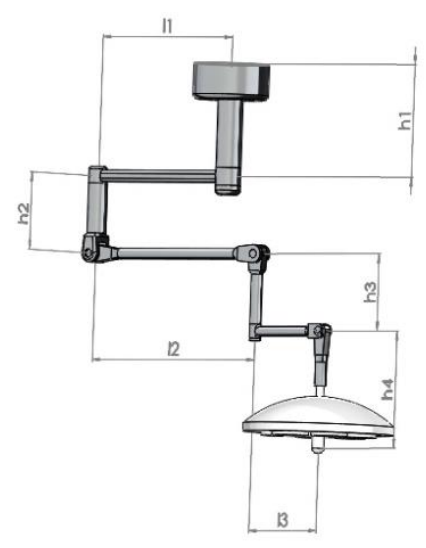

Şekil 2. Manipülatörün katı modeli 

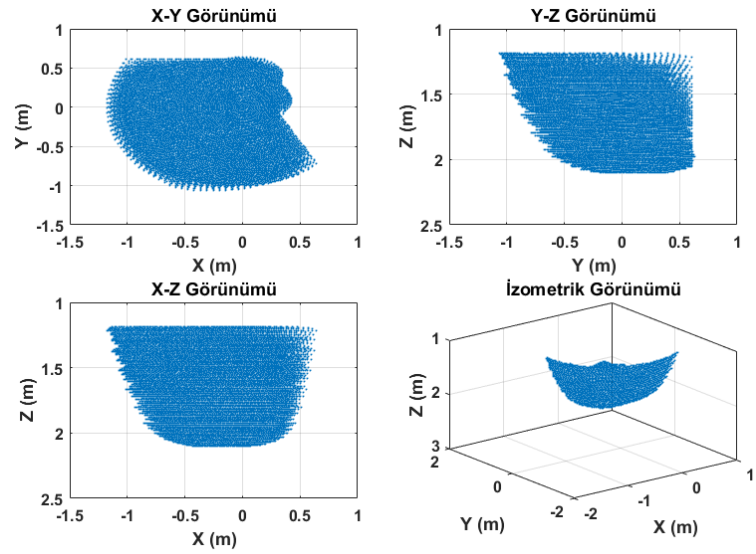

Şekil 3. Manipülatörün çalışma uzayı

\subsection{Aydınlatma Manipülatörü}

$\mathrm{Bu}$ çalışmada kullanılan altı eklemli aydınlatma manipülatörü tıbbı operasyon alanı aydınlatması için tasarlanmıştır. Elle ayarlanan tıbbi operasyon alanı aydınlatmasında kullanılan bir aydınlatma başlığı, aydınlatma manipülatörünün tasarımında örnek model olarak alınmıştır. Altı döner eklemli olan bu manipülatörün üç boyutlu katı modeli Şekil 2'de verilmiştir. Her eklem bağımsız elektrik motorları ile tahrik edilmektedir. Manipülatörün ileri kinematik hesabında kullanılan D-H parametreleri ve eklemlerin çalışma aralıkları Tablo 1.'de verilmiştir. Tasarlanan konfigürasyon ve eklemler için belirlenen açısal konum sınırlarına bağlı manipülatörün çalışma uzayı Şekil.3'te verilmiştir. Eklemlere atanan koordinatlar arasındaki dönüşüm matrisleri eşitlik 1-7'de verilmiştir. Uç işlevcinin (aydınlatma başlı̆̆ı) referans koordinat sistemine göre uzayda konum ve yönelimini ifade eden dönüşüm matrisi Eşitlik 1-7'de verilen dönüşüm matrislerinin ileri yönlü çarpılmasıyla elde edilir.

Tablo 1. Manipülatörün D-H parametreleri.

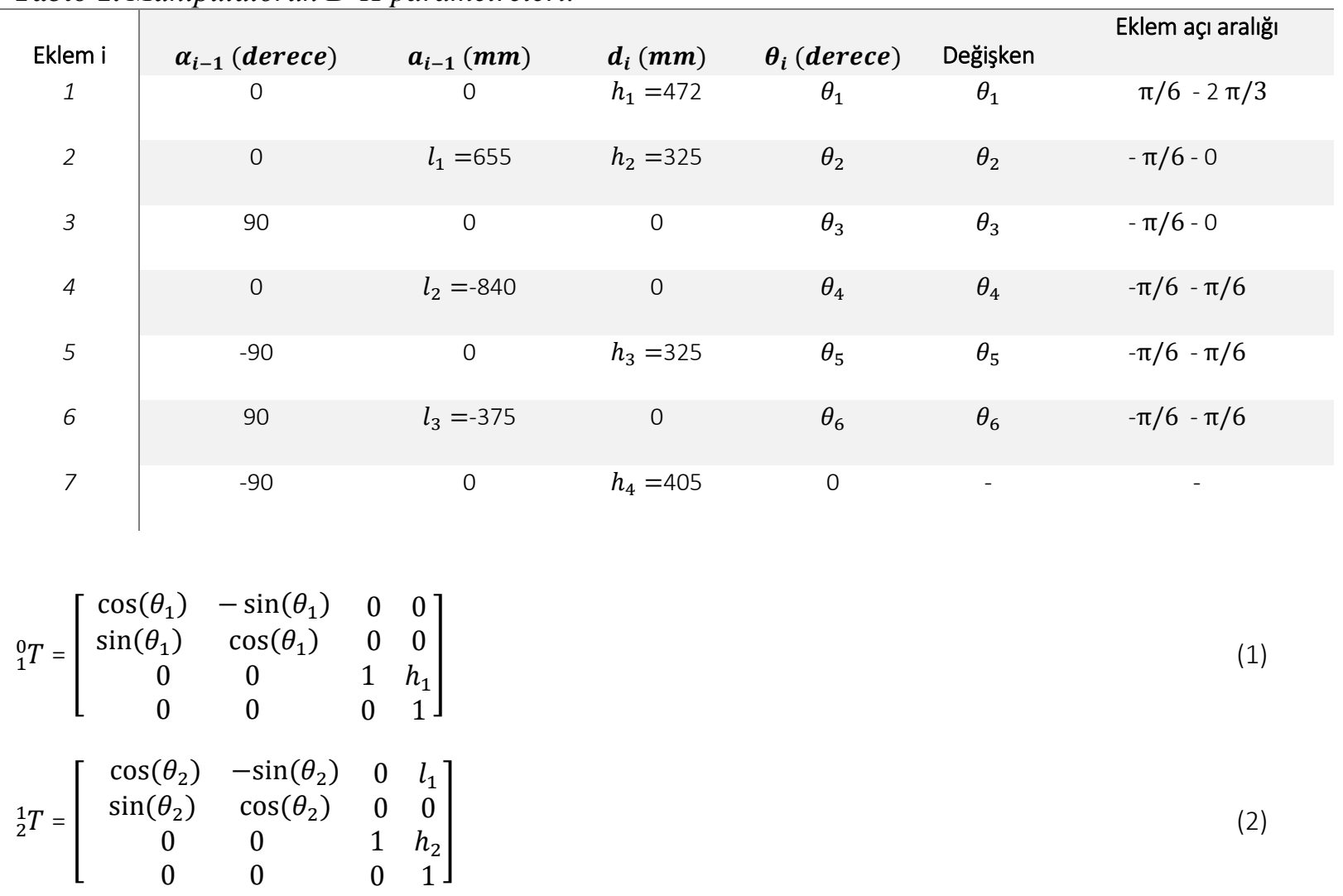


${ }_{3}^{2} T=\left[\begin{array}{cccc}\cos \left(\theta_{3}\right) & -\sin \left(\theta_{3}\right) & 0 & 0 \\ 0 & 0 & -1 & 0 \\ \sin \left(\theta_{3}\right) & \cos \left(\theta_{3}\right) & 0 & 0 \\ 0 & 0 & 0 & 1\end{array}\right]$

${ }_{4}^{3} T=\left[\begin{array}{cccc}\cos \left(\theta_{4}\right) & -\sin \left(\theta_{4}\right) & 0 & -l_{2} \\ \sin \left(\theta_{4}\right) & \cos \left(\theta_{4}\right) & 0 & 0 \\ 0 & 0 & 1 & 0 \\ 0 & 0 & 0 & 1\end{array}\right]$

${ }_{5}^{4} T=\left[\begin{array}{cccc}\cos \left(\theta_{5}\right) & -\sin \left(\theta_{5}\right) & 0 & 0 \\ 0 & 0 & 1 & h_{3} \\ -\sin \left(\theta_{5}\right) & -\cos \left(\theta_{5}\right) & 0 & 0 \\ 0 & 0 & 0 & 1\end{array}\right]$

${ }_{6}^{5} T=\left[\begin{array}{cccc}\cos \left(\theta_{6}\right) & -\sin \left(\theta_{6}\right) & 0 & -l_{3} \\ 0 & 0 & -1 & 0 \\ \sin \left(\theta_{6}\right) & \cos \left(\theta_{6}\right) & 0 & 0 \\ 0 & 0 & 0 & 1\end{array}\right]$

${ }_{7}^{6} T=\left[\begin{array}{rrrr}1 & 0 & 0 & 0 \\ 0 & 0 & 1 & h_{4} \\ 0 & -1 & 0 & 0 \\ 0 & 0 & 0 & 1\end{array}\right]$

${ }_{7}^{0} T=\left[\begin{array}{cccr}r 11 & r 12 & r 13 & P x \\ r 21 & r 22 & r 23 & P y \\ r 31 & r 32 & r 33 & P z \\ 0 & 0 & 0 & 1\end{array}\right]$

Eşitlik 8'de genel formu verilen bu matrisin ri,j elemanları uç işlevcinin referans koordinat sistemine göre yönelimine ait eşitlikleri temsil ederken, Px, Py ve Pz elemanları referans koordinat sistemine göre uç işlevcinin sırasıyla X, Y ve Z konum eşitliklerini temsil etmektedir. Bu eşitlikler oldukça karmaşık, altı değişkene sahip ve lineer olmayan eşitlikler olması nedeni ile analitik veya geometrik yöntemlerle çözümünün olmamasından dolayı ters kinematik probleminin çözümünde YSA kullanılmıştır.

\subsection{YSA ile Ters Kinematik Problemi Çözümü}

YSA genellikle lineer olmayan çok girişli ve çok çıkışlı sistemlerde girişler ve çıkışlar arasında ilişki kuran, paralel çalışan elemanlardan oluşan bir sinir ağları sistemidir. Biyolojik sinir ağlarının çalışma prensibine dayanan bu ağ sisteminde, elemanlar arasındaki bağlantı şekilleri (ağırlıklar) sinir ağının işlevini belirler. Bir sinir ağı, ağırlıklar değiştirilerek belirli girişlere karşı istenen hedef çıktıları elde etmek için eğitilir [21]. YSA yapısı genelde giriş katmanı, gizli katman ve çıkış katmanı olmak üzere üç ana bölümden oluşur. Giriş katmanındaki değerler, gizli katmandaki değerlerin çeşitli öğrenme algoritmalarıyla ayarlanmasıyla çıkış katmanındaki değerleri verecek şekilde eşlenir. Çalışmanın amacı tasarlanan robotun ters kinematik probleminin YSA temelli çözülmesidir.

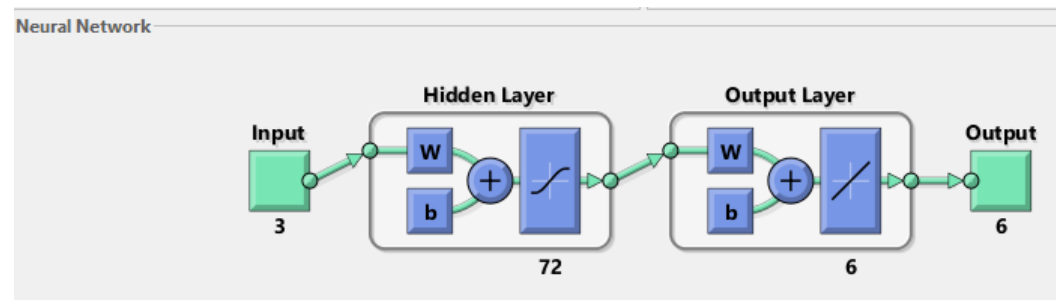

Şekil 4. YSA yapısının Şematik Gösterimi 
Matlab birçok farklı alandaki akademik çalışmalarda sıklıkla kullanılan, oldukça güçlü bütünleşik araç kutuları olan, çok amaçlı bir programdır. Araç kutularından Neural Network Toolbox ise sinir ağları oluşturmak, eğitmek, görselleştirmek ve benzetim elde etmek için algoritmalar, önceden eğitim görmüş modeller ve uygulamalar içermektedir. Bu araç kutusu yardımı ile sınıflandırma, kümeleme, boyut azaltma, zaman serisi öngörme ve dinamik sistem modelleme ve denetimi gerçekleştirilebilmektedir. Çalışmaya konu olan manipülatör için tasarlanan sinir ağının oluşturulması ve eğitimi için bu araç kutusundan faydalanılmıştır. Neural Networks Toolbox hakkında daha geniş bilgiye Ref. [21]'den ulaşılabilir.

YSA'nın eğitimi için gerekli giriş ve hedef veri setleri, manipülatörün ileri kinematik çözümü kullanılarak elde edilmiştir. Hedef değerleri, her bir eklemin açısal konumlarının belirlenen adım aralığı $(0.1 \pi)$ ile artırılarak 6x1533312 şeklinde bir matris halinde oluşturulmuştur. YSA'nın performans1, eğitimde kullanılan veri sayısıyla doğrudan ilişkili olduğu için adım aralığı oldukça küçük seçilmiştir. Giriş değerleri ise belirlenen açısal konumlara karşılık ileri kinematik ile hesaplanan X,Y,Z konumlarını içeren 3x1533312 şeklinde bir matris halinde oluşturulmuştur. Neural Networks Toolbox aracilığ1 ile Matlab ortamında oluşturulan sinir ağın şematik yapısı Şekil 4'te gösterilmektedir. İleri beslemeli ve çok katmanlı bir yapıya sahip YSA'nın eğitimi için Levenberg-Marquardt geri-yayılım algoritması kullanılmıştır. Veri setlerinin \%70'i eğitim, \% 15'i doğrulama ve \%15'i test için kullanılmıştır. Aynı veri setleri ile gizli katmanın nöron sayıları değiştirilerek birkaç kez yapılan eğitimler neticesinde, iterasyon adedi, eğitim süresi ve ağ performansı gibi parametreler göz önüne alındığında en iyi sonucu gizli katmanda 72 nöron olan ağ yapısı vermiştir. Şekil 5'te eğitim performansını gösteren regresyon grafikleri verilmiştir.
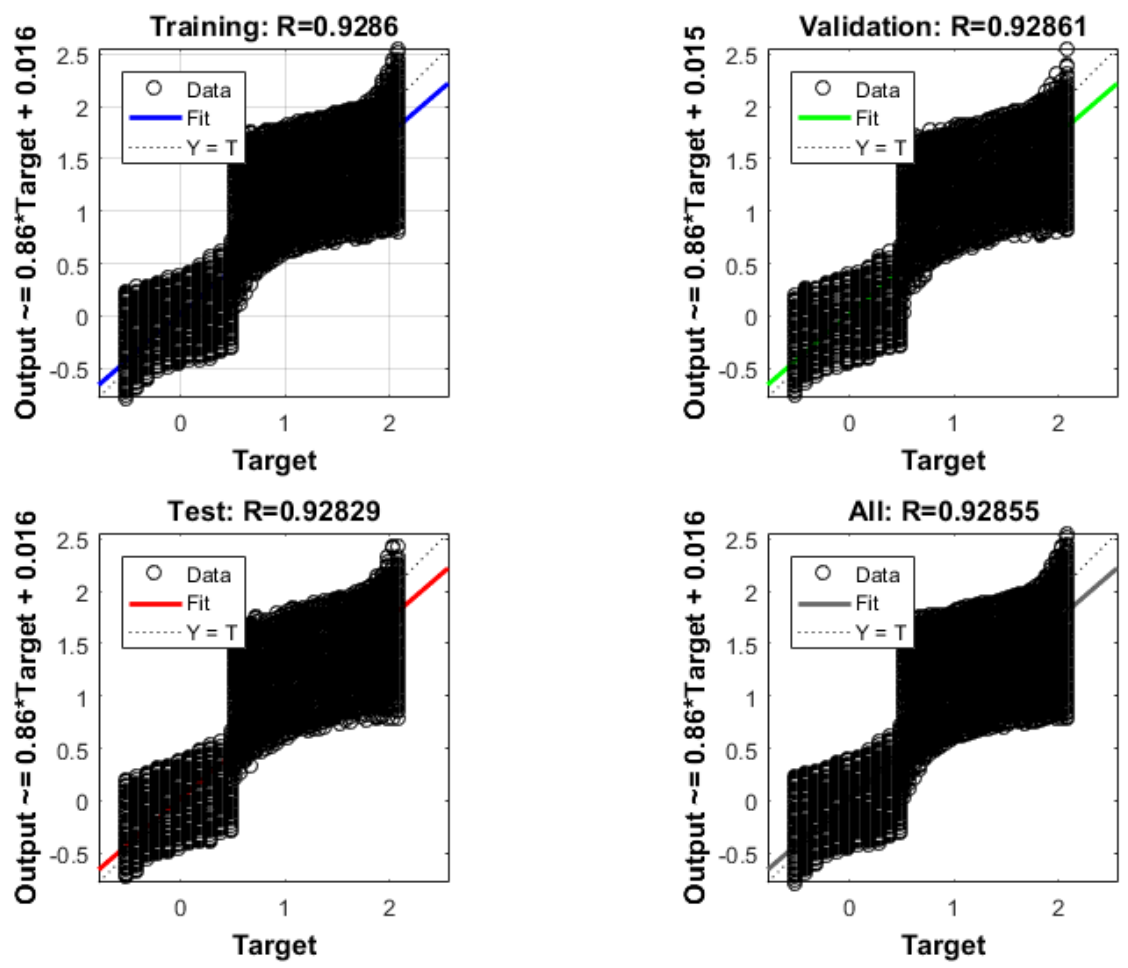

Şekil 5. YSA ę̆itim performansl

\section{BULGULAR}

YSA eğitildikten sonra, bir test giriş verisi ağın eklem açılarını tahmin etmesi için tanımlanmıştır. Ağın tahmin ettiği eklem açıları ve bu açılara karşılık gelen konum hataları farklı noktalar için Tablo 2'de verilmiştir. Birkaç takım örnek noktalar için kabul edilebilir tahminler elde edildikten sonra aydınlatma başlı̆̆ının takip etmesi için Kartezyen koordinatlarda farklı yörüngeler tanımlanmıştır. Tanımlanan 
yörüngelere karşılık eklem uzayındaki açısal konumlar eğitilen YSA'dan elde edilmiştir. Aydınlatma başlığının takip etmesi istenen yörünge olarak çalışma uzayı içerisinde dikdörtgene benzer şekle sahip bir yörünge ve rastgele noktalar seçilerek belirlenen bir yörünge olmak üzere iki farklı yörünge seçilmiştir.

Tablo 2. Istenen konumlara karşılık YSA tarafindan tahmin edilen eklem açıları ve konum hataları.

\begin{tabular}{|c|c|c|c|c|c|c|c|c|c|c|}
\hline \multirow{2}{*}{ Theta } & \multicolumn{3}{|c|}{ İstene konum (m) } & \multirow{2}{*}{$\begin{array}{l}\text { Tahmin } \\
\text { edilen açı } \\
\text { (rad) }\end{array}$} & \multicolumn{3}{|c|}{ Tahmin edilen açılara karşılık konumlar (m) } & \multicolumn{3}{|c|}{ Mutlak Konum Hatası (mm) } \\
\hline & $x$ & $Y$ & Z & & $x$ & $\mathrm{Y}$ & Z & $x$ & $Y$ & $z$ \\
\hline$\theta_{1}$ & \multirow{6}{*}{-0.6976} & \multirow{6}{*}{-0.4955} & \multirow{6}{*}{1.5890} & 1.4224 & \multirow{6}{*}{-0.6947} & \multirow{6}{*}{-0.5090} & \multirow{6}{*}{1.5974} & \multirow{6}{*}{2.9} & \multirow{6}{*}{9.5} & \multirow{6}{*}{8.7} \\
\hline$\theta_{2}$ & & & & -0.3949 & & & & & & \\
\hline$\theta_{3}$ & & & & -0.1857 & & & & & & \\
\hline$\theta_{4}$ & & & & 0.3108 & & & & & & \\
\hline$\theta_{5}$ & & & & -0.1612 & & & & & & \\
\hline$\theta_{6}$ & & & & 0.3029 & & & & & & \\
\hline$\theta_{1}$ & \multirow{6}{*}{-0.7758} & \multirow{6}{*}{-0.2521} & \multirow{6}{*}{1.5180} & 0.9899 & \multirow{6}{*}{-0.7829} & \multirow{6}{*}{-0.2566} & \multirow{6}{*}{1.5196} & \multirow{6}{*}{7.1} & \multirow{6}{*}{4.5} & \multirow{6}{*}{1.6} \\
\hline$\theta_{2}$ & & & & -0.3484 & & & & & & \\
\hline$\theta_{3}$ & & & & -0.1001 & & & & & & \\
\hline$\theta_{4}$ & & & & 0.2690 & & & & & & \\
\hline$\theta_{5}$ & & & & -0.0878 & & & & & & \\
\hline$\theta_{6}$ & & & & 0.1802 & & & & & & \\
\hline
\end{tabular}

Aydınlatma manipülatörünün yörünge takip benzetimi Matlab/Simulink ortamında gerçekleştirilmiştir. Simulink blok diyagramı Şekil 6'da gösterilmektedir. Şekilde görünen Yörünge bloğu, istenen yola ait konum bilgilerini içermektedir, Ağ bloğunda ise eğitim sonucu elde edilmiş YSA modeli vardır. Kontrol bloğunda her bir eklemin açısal konumunu kontrol eden PID kontrolcüler vardır. Bu PID kontrolcülerin kazançları Simulink içerisinde olan PID Controller Tuning yardımıyla otomatik olarak belirlenmiştir. Sistem bloğu, katı modelin Simulink ortamına aktarılması sonucu elde edilen ve Simulink'te fiziksel modelleme için kullanılan bloklardan oluşmaktadır. Bu bloklar, manipülatöre ait kütle, atalet momenti, boyutlar, yoğunluk gibi fiziksel özellikleri içermektedir. Ağ bloğu referans koordinat girişine karş1lik eklemlerin açısal konumlarını tahmin etmektedir. Kontrol bloğu, Ağ bloğu çıkışı olan açısal konumlar ve Sistem bloğundan gelen açısal konumların geri beslemesine göre kontrolcü çıkışlarını üretmektedir.

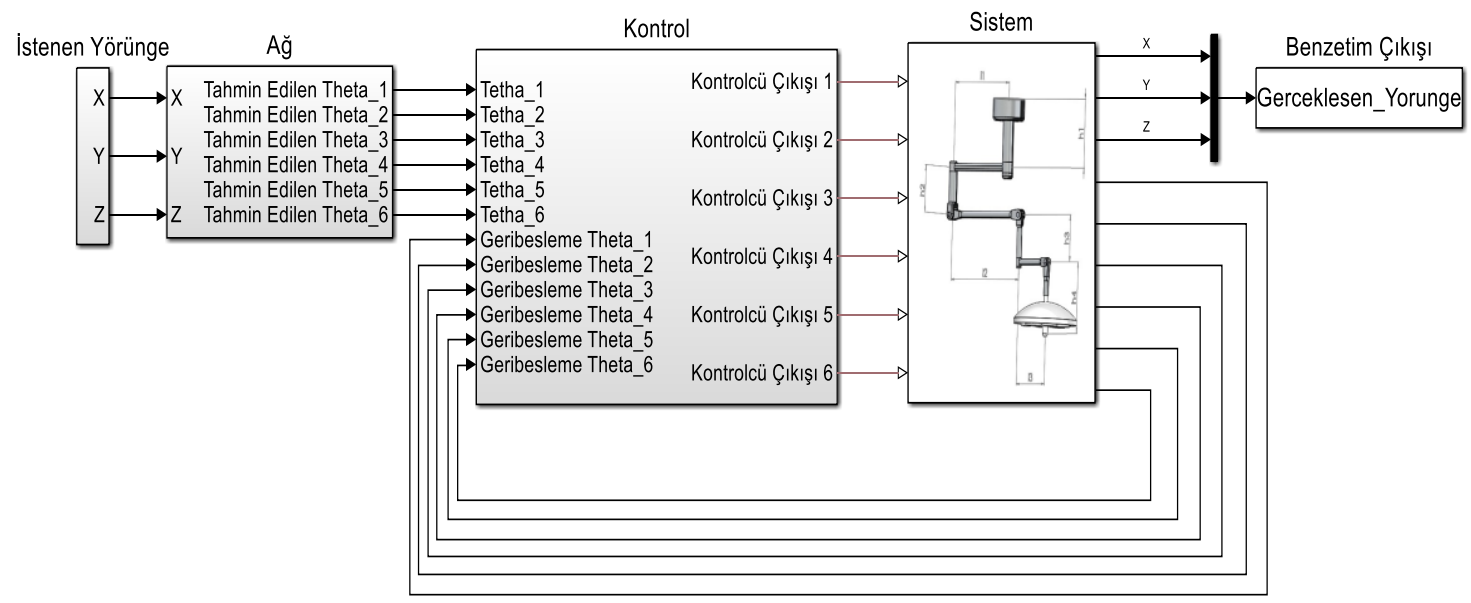

Şekil 6. Simulink model blok diyagramı 
$\mathrm{Bu}$ kontrolcü çıkışları sistemin girişi olarak kullanılmaktadır. Sistem bloğunun çıkışı olarak eklemlerin açısal konumları ve aydınlatma başlığının X,Y,Z konum koordinatları elde edilmektedir. Benzetim sonucu gerçekleşen yörüngeler ve istenen yörüngeler Şekil 7-8'de gösterilmiştir. Bilindiği üzere aydınlatmanın odak noktasından uzaklaştıkça 1şık şiddeti azalmaktadır. Ancak grafikte görüldüğü gibi aydınlatma robotunun konumundaki milimetrik hatanın istenen odak noktasındaki 1şı şiddetine etkisi tolere edilebilir düzeyde olacaktır.

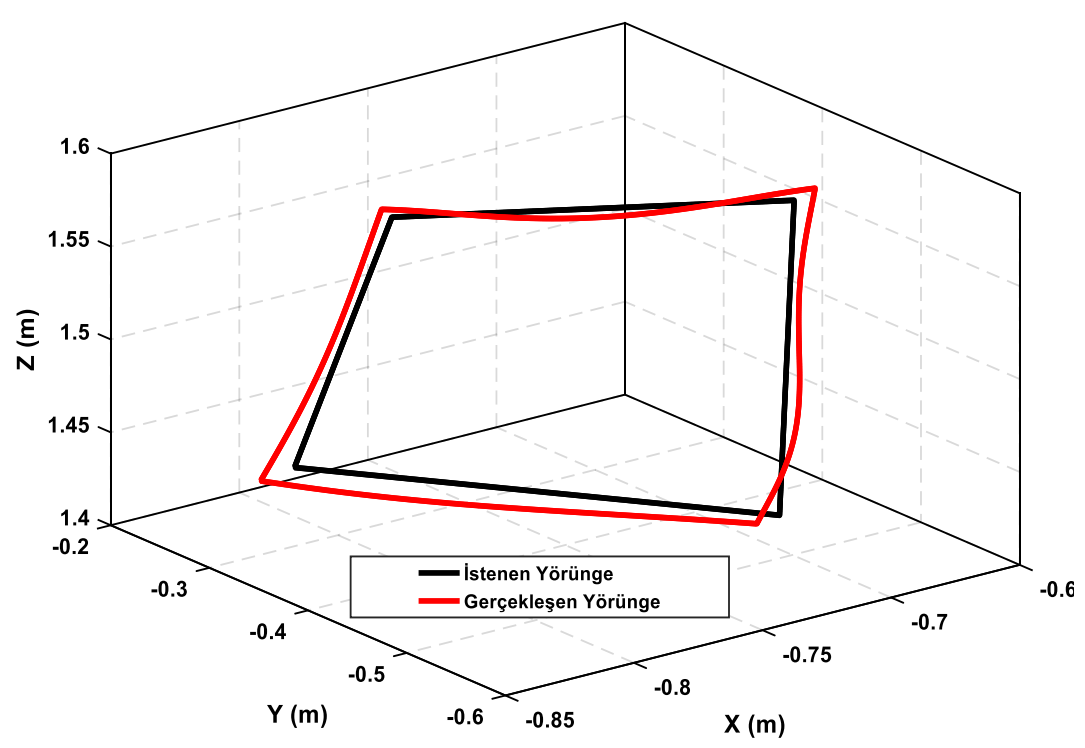

Şekil 7. Dikdörtgen benzeri referans yörünge ve gerçekleşen yörünge

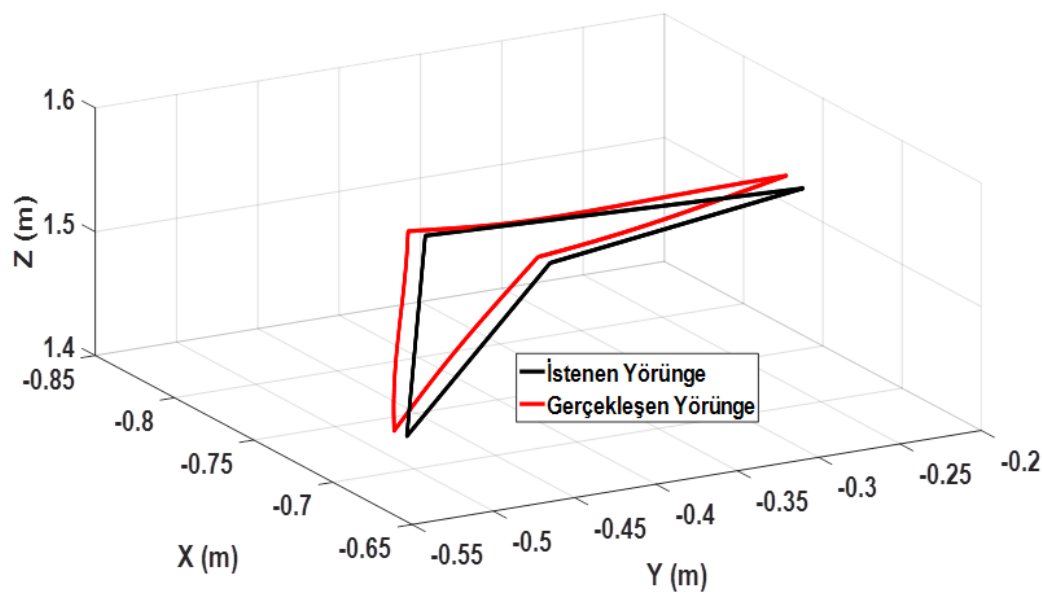

Şekil 8. Rastgele noktalarla belirlenen referans yörünge ve gerçekleşen yörünge

\section{TARTIŞMA VE SONUÇ}

$\mathrm{Bu}$ çalışmada tıbbi operasyonların aydınlatmasında kullanılmak üzere tasarlanan altı uzuvlu bir aydınlatma manipülatörünün ters kinematik probleminin çözümü sunulmuştur. Ters kinematik problemi literatürde bu tip problemlerin çözümünde sıklıkla kullanılan YSA ile gerçekleştirilmiştir. Elde edilen sonuçlara bakıldığında YSA'nın ters kinematik için gerekli olan eklem değişkenlerini tahmin etmedeki doğruluğu kabul edilebilir düzeydedir. YSA'nın performansı, YSA'nın eğitiminde kullanılan algoritma ve parametreler ile doğrudan alakalıdır. 
Literatürdeki ters kinematik problem çözümüne YSA' nın uygulandığı çalışmalar ile bu çalışmanın konusu olan aydınlatma robotunun ters kinematik problem çözümünden elde edilen sonuçların başarımı örtüşmektedir. Bu çalışmadan elde edilen sonuçlar ile YSA'nın karmaşık yapıdaki manipülatörlerin ters kinematik probleminin çözümünde oldukça başarılı ve hızlı bir yöntem olduğu görülmüştür. Ayrıca, kabul edilebilir hatalar dâhilinde bu çalışmada incelenen aydınlatma manipülatörünün kontrolünün YSA ile gerçekleştirilebileceği gösterilmiştir.

\section{KAYNAKLAR}

[1]. Alavandar, S., Nigam, M.J. 2008. Neuro-Fuzzy based Approach for Inverse Kinematics Solution of Industrial Robot Manipulators. Int. J. of Computers, Communications \& Control, 3(2008), 224-234.

[2]. Yildirim, Ş., Eski, İ. 2006. A QP Artificial Neural Network Inverse Kinematic Solution for Accurate Robot Path Control. Journal of Mechanical Science and Technology, 20(7), 917-928.

[3]. Köker, R. 2013. "A Genetic algorithm approach to a neural-network-based inverse kinematics solution of robotic manipulators based on error minimization" Information Sciences 222(2013), 528-543.

[4]. Köker, R. 2011. "A neuro-genetic approach to the inverse kinematics solution of robotic manipulators" Scientific Research and Essays, 6 (13), 2784-2794.

[5]. Duka, A.V. 2014. Neural network based inverse kinematics solution for trajectory tracking of a robotic arm. Procedia Technology, 12(2014), 20 - 27.

[6]. Bingül Z., Karahan, O. 2011. A Fuzzy Logic Controller tuned with PSO for 2 DOF robot trajectory control. 38(1), 1017-1031.

[7]. Yahya, S., Moghavvemi, M. 2014. Artificial neural networks aided solution to the problem of geometrically bounded singularities and joint limits prevention of a three dimensional planar redundant manipülatör. Neuro Computing 137(2014), 34-36.

[8]. Küçük, S., Bingül, Z. 2014. Inverse kinematic solutions for industrial robot manipulators with offset wrists. Applied Mathematical Modeling, 38(2014), 1983-1999.

[9]. Luv, A., Kush, A., Ruth. J. 2014. Use of artificial neural networks for the development of an inverse kinematic solution and visual identification of singularity zone(s) Procedia CIRP, 17(2014), 812 817.

[10].Mashhadany, Y. I. 2012. ANFIS-Inverse-Controlled PUMA 560 Workspace Robot with Spherical Wrist. Procedia Engineering, 41(2012), 700 - 709.

[11].Köker, Öz, R. C., Çakar, T., Ekiz, H. 2004. A study of neural network based inverse kinematics solution for a three-joint robot. Robotics and Autonomous Systems, 49(2004), 227-234.

[12].Chaudhary, H., Prasad, R., Sukavanum, N. 2012. Position analysis based approach for trajectory tracking control of scorbot-er-v plus robot manipülatör. International Journal of Advances in Engineering \& Technology, 3(2), 253-264.

[13].Jha P., Biswal, BB., 2014. A Neural Network Approach for Inverse Kinematic of a SCARA Manipulator. International Journal of Robotics and Automation (IJRA), 3(1), 52-61.

[14].Almusawi, ARJ., Dülger, LC., Kapucu, S. 2016 A New Artificial Neural Network Approach in Solving Inverse Kinematics of Robotic Arm (Denso VP6242). Research Article Hindawi Publishing Corporation Computational Intelligence and Neuroscience, Volume 2016, Article 10 pages. 
[15].Nanda S.K., Panda, S., Subudhi S.P., Das K.R., 2012. A Novel Application of Artificial Neural Network for the Solution of Inverse Kinematics Controls of Robotic Manipulators. I.J. Intelligent Systems and Applications, 9(2012), 81-91.

[16].Yin F., Wang Y.N., Wei, S.N. 2011. Inverse Kinematic Solution for Robot Manipulator Based on Electromagnetism-like and Modified DFP Algorithms. Acta Automatica Sinica, 37(1), 74-82.

[17].Hoang, N-B., Kang H-J. 2016. Neural network-based adaptive tracking control of mobile robots in the presence of wheel slip and external disturbance force. Neuro computing, 188(2016), 12-22.

[18].Karaatl1, M., Albeni, M. 2011. Forecasting rose flower planting areas using artificial neural networks. Akdeniz University International Journal of Alanya Faculty of Business, 3(2), 137-149.

[19].Karlık, B., Cemel, S. 2012. Diagnosing diabetes from breath odor using artificial neural networks" Turkiye Klinikleri J Med Sci 32(2):331-336.

[20].Çakır, Ş., Ertunç, H.M., Ocak, H. 2009. A Case Study for Identification of Texture in Carbonate Rocks Using Artificial Neural Networks: Akveren Formation. Uygulamalı Yerbilimleri 2(2009), 71 79.

[21].Beale, M.H., Hagan, M.T., Demuth, H.B. 2017. PDF Documentation for Neural Network Toolbox.https://www.mathworks.com/help/pdf_doc/nnet/index.html?s_cid=doc_ftr (Erişim Tarihi: 10.04.2017). 